\title{
Serum leptin levels in overweight children and adolescents
}

\author{
Henedina Antunes ${ }^{1,2}$, Cristina Santos $^{3}$ and Susana Carvalho ${ }^{1}$ \\ ${ }^{1}$ Gastroenterology, Hepatology and Nutrition Unit, Paediatric Department, S. Marcos Hospital, Braga, Portugal \\ ${ }^{2}$ Life and Health Sciences Research Institute (ICVS), School of Health Sciences, University of Minho, Campus de Gualtar, \\ 4709-057 Braga, Portugal \\ ${ }^{3}$ Biostatistics and Medical Informatics Department, Faculty of Medicine, Porto University, Portugal
}

(Received 11 January 2008 - Revised 30 June 2008 - Accepted 18 July 2008 - First published online 28 August 2008)

Leptin is an adipocyte-secreted hormone which plays a key role in energy homeostasis. Our aim was to determine the relationship between serum leptin and clinical and biochemical features in overweight children and adolescents. Overweight children and adolescents followed in this Unit with serum leptin ascertained were included. Clinical, biochemical and abdominal ultrasound data were analysed. Statistical analysis was performed by $t$ test, $\chi^{2}$, Pearson's correlation and linear regression. One outlier of serum leptin was excluded to perform correlation and regression. Serum leptin was determined in 357 patients. At the first visit, the mean age was 9.5 (SD 3.2) years and mean BMI $z$-Score was 1.72 (SD 1.34) (girls 1.71 (SD 1.16); boys 1.72 (SD 1.11)). Serum leptin levels were significantly related to: sex (mean: girls $48.0 \mathrm{ng} / \mathrm{ml}$, boys $34.4 \mathrm{ng} / \mathrm{ml} ; P=0.003$ ); Tanner stage (mean: I-II $37.0 \mathrm{ng} / \mathrm{ml}$, III-V $45.2 \mathrm{ng} / \mathrm{ml} ; P=0.035$ ); systolic blood pressure (mean: normal $41.3 \mathrm{ng} / \mathrm{ml}$, high $44.0 \mathrm{ng} / \mathrm{ml}$; $P=0.009)$; BMI $z$-score $(r 0.136 ; P=0.010)$; C-peptide $(r 0.17 ; P=0.002)$; insulin $(r 0.34 ; P<0 \cdot 001)$; homeostasis model assessment of insulin resistance (HOMA-IR) $(r 0.25 ; P<0.001)$ and aspartate aminotransferase $(r-0.12 ; P=0.023)$. In the multivariate analysis (with leptin as the dependent variable and sex, Tanner stage, BMI $z$-score, systolic blood pressure, aspartate aminotransferase, C-peptide, insulin and HOMA-IR as independent variables), sex and BMI were determinant factors. The present study in overweight children and adolescents showed that being female and greater BMI were significantly and independently associated with increased serum leptin. In this large cohort other associations with leptin described in the literature can be discharged.

Leptin: Childhood overweight: Sex: Body mass index

Obesity prevalence has been increasing among children and adolescents as it has in adults ${ }^{(1)}$. In the USA, the obesity and overweight prevalence in 2003-4 was 17.1 and $33.6 \%$ respectively among children and adolescents aged 2-19 years $^{(1)}$. In Europe, Portugal has the second highest overweight prevalence in children, $31.5 \%$, immediately after Italy, and $11.3 \%$ are obese ${ }^{(2)}$.

Leptin is a $16 \mathrm{kDa}$ peptide hormone codified by the $o b$ gene which is located at chromosome $7(7 \mathrm{q} 31.1)^{(3)}$. It is synthesised mainly by adipose tissue and secreted to plasma, but other tissues such as the stomach, intestines, placenta and testes also secrete leptin ${ }^{(4)}$. It regulates the expression of hypothalamic neuropeptides involved in energy metabolism by suppressing food intake and stimulating energy expenditure ${ }^{(4-6)}$.

At first, it was thought that human obesity might occur as a result of lack of leptin (as in the ob/ob mouse). However, it was found that the majority of humans did not lack leptin; in contrast they had circulating leptin concentrations that were highly correlated with adipose tissue mass ${ }^{(7)}$.

Leptin has effects on different systems of the body: central nervous system (inhibition of food intake, reduction of adipose mass, increased thermogenesis), glucose homeostasis, reproductive system (signalling onset of puberty, maintenance of reproductive function), autonomic nervous system, haematopoietic system, skeletal system, oncogenesis and transplantation (contributing to rejection of transplants) ${ }^{(4)}$.

The aim of the present study was to determine the relationship between serum leptin levels and clinical and biochemical features in overweight children and adolescents.

\section{Subjects and methods}

Overweight children and adolescents followed in a Paediatric Gastroenterology, Hepatology and Nutrition Unit from 1 February 1999 to 13 November 2006 who had had serum leptin levels determined were included in the study.

Clinical assessment included detailed history and physical examination: weight, height, Tanner stage, systolic and diastolic blood pressure, waist circumference, acanthosis nigricans and stretch marks. Weight measurement was performed using two different electronic equipments according to age (above 2 years, SECA model 763; under 2 years, SECA model 727; SECA GmbH and Co., Hamburg, Germany). Blood pressure was measured three times with a cuff appropriate to each arm size after $5 \mathrm{~min}$ rest. High blood pressure was considered when it was above the 95th percentile

Abbreviation: HOMA-IR, homeostasis model assessment of insulin resistance. 
for age and sex. Waist circumference was measured by the same physician directly over the skin at a level midway between the lower rib margin and the iliac crest. Blood samples were collected after an overnight fast between 08.00 and 10.00 hours and the parameters analysed included glucose, aminotransferases (alanine aminotransferase, aspartate aminotransferase), total cholesterol, HDL and LDL, TAG, serum leptin, C-peptide and insulin. Leptin was measured by immunoradiometric assay (DSL-23100i ACTIVE ${ }^{\circledR}$ Human Leptin IRMA; Diagnostic Systems Laboratories Inc., Webster, TX, USA). Abdominal ultrasound was performed by the same physician to search for steatosis: increased hepatic parenchymal echotexture and vascular blurring ${ }^{(8)}$. BMI was calculated by the standard formula $\left(\mathrm{kg} / \mathrm{m}^{2}\right)$. TAG, total cholesterol, HDL and LDL were analysed according to age and sex ${ }^{(9)}$.

Overweight was defined as BMI above the 85 th percentile and obesity above the 95th percentile for age and sex according to the Centers of Disease Control ${ }^{(10)}$. BMI and waist circumference $z$-score were calculated ${ }^{(11)}$. Insulin resistance was determined by the homeostasis model assessment of insulin resistance (HOMA-IR) ${ }^{(10)}$. Non-alcoholic fatty liver disease was considered in the presence of elevated aminotransferases and/or steatosis in abdominal ultrasound, when other causes were excluded ${ }^{(12)}$.

Statistical analysis was performed in the Statistical Package for Social Sciences (version 15.0; SPSS Inc., Chicago, IL, USA) using $t$ tests, $\chi^{2}$, Pearson's correlation and linear regression. One outlier of serum leptin was excluded to perform correlation and regression. Significance was considered when $P$ was below $0 \cdot 05$.

The Ethical Committee of S. Marcos Hospital approved the present study.

\section{Results}

The present study included 357 overweight children and adolescents with serum leptin levels determined; $53.2 \%$ were girls. The median age of obesity onset was 3 years (range 1-13 years). The majority of patients were previously healthy; thirty-five patients had a previous diagnosis of asthma and one patient had a previous diagnosis of diabetes mellitus. There was a history of overweight in first-degree relatives in $62 \%$, arterial hypertension in $27.7 \%$, type 2 diabetes mellitus in $8.8 \%$ and dyslipidaemia in $32.9 \%$. At the first visit, the mean age was 9.5 (SD 3.2) years and its distribution was similar in both sexes (girls, 9.2 years; boys, 9.7 years, $P=0.154$ ). The mean BMI $z$-score was 1.72 (SD 1.34), in girls it was 1.71 (SD 1.16) and in boys it was 1.72 (SD 1.11).

Obesity was found in 330 children and adolescents (176 girls and 154 boys) and BMI was between the 85th and 95th percentiles in twenty-seven children (fourteen girls and thirteen boys); $19.4 \%$ had a BMI above $30 \mathrm{~kg} / \mathrm{m}^{2}$ and $5.9 \%$ above $35 \mathrm{~kg} / \mathrm{m}^{2}$. The mean waist circumference $z$-score was 1.58 (SD 1.05), 30.5\% had acanthosis nigricans and $17 \%$ had stretch marks. There was high systolic blood pressure in $21.6 \%$ and high diastolic blood pressure in $6.7 \%$ ( $n$ 274).

The blood analysis results are shown in Table $1^{(9,13)}$. There was hyperglycaemia $(>5.6 \mathrm{mmol} / \mathrm{l})$ in $4.5 \%$, high total cholesterol in $17.5 \%$, low HDL in $13.2 \%$, high LDL in $10.7 \%$, high TAG in $22.1 \%$, insulin resistance in $54.9 \%$, C-peptide above $0.73 \mathrm{nmol} / \mathrm{l}$ in $47.9 \%$ and increased leptin levels, by sex and Tanner stage, in $93.6 \%$.

The abdominal ultrasound revealed steatosis in $26.7 \%$ ( $n$ 195). Non-alcoholic fatty liver disease was present in $46.4 \%$ (n 224).

Serum leptin levels were significantly related to sex, Tanner stage, systolic blood pressure, BMI $z$-score, C-peptide, insulin, HOMA-IR and aspartate aminotransferase (Tables 1 and 2). We found no correlation between serum leptin and lipid profile or blood glucose.

In boys ( $n$ 166), leptin was significantly related to insulin ( $r$ 0.364; $P<0.001)$ and HOMA-IR $(r$ 0.313; $P<0.001)$; it was not significantly related to BMI $z$-score $(r 0.142 ; P=0.068)$. In girls ( $n$ 190), leptin levels were significantly related to Tanner stage (mean: I-II $40.4 \mathrm{ng} / \mathrm{ml}, \mathrm{III}-\mathrm{V} 53.7 \mathrm{ng} / \mathrm{ml} ; P=0 \cdot 009)$, BMI

Table 1. Associations ( $r$, Pearson's test) between serum leptin levels ( $\mathrm{ng} / \mathrm{ml}$ ) and clinical and laboratory characteristics (Mean values and standard deviations and correlation coefficients)

\begin{tabular}{|c|c|c|c|c|c|c|}
\hline & Mean & SD & $r$ & $P$ & Subjects $(n)$ & Reference values \\
\hline Fasting leptin (ng/ml) & $42 \cdot 3$ & $28 \cdot 7$ & & & 356 & $\dagger$ \\
\hline Waist circumference $(\mathrm{cm})$ & $86 \cdot 3$ & $12 \cdot 9$ & $0.27^{\star}$ & $<0.001$ & 332 & \\
\hline Waist circumference $z$-score & 1.58 & 1.05 & 0.10 & 0.059 & 332 & \\
\hline BMI $\left(\mathrm{kg} / \mathrm{m}^{2}\right)$ & $26 \cdot 8$ & $4 \cdot 4$ & $0 \cdot 35^{\star}$ & $<0.001$ & 356 & \\
\hline BMI z-score & 1.72 & $1 \cdot 34$ & $0 \cdot 136$ & 0.010 & 356 & \\
\hline Fasting glucose (mmol/l) & $4 \cdot 7$ & $1 \cdot 1$ & 0.03 & 0.581 & 350 & $3 \cdot 9-5 \cdot 8$ \\
\hline Total cholesterol (mmol/l) & $4 \cdot 4$ & 0.9 & 0.03 & 0.951 & 324 & $\ddagger$ \\
\hline $\mathrm{HDL}(\mathrm{mmol} / \mathrm{l})$ & $1 \cdot 3$ & 0.3 & -0.08 & $0 \cdot 155$ & 316 & $\ddagger$ \\
\hline $\mathrm{LDL}(\mathrm{mmol} / \mathrm{l})$ & $2 \cdot 6$ & 0.8 & -0.09 & 0.179 & 223 & $\ddagger$ \\
\hline TAG (mmol/l) & $1 \cdot 1$ & $1 \cdot 3$ & -0.009 & 0.869 & 352 & $\ddagger$ \\
\hline Fasting insulin (pmol/l) & $98 \cdot 6$ & $143 \cdot 9$ & $0.34^{\star}$ & $<0.001$ & 346 & $41 \cdot 7-187 \cdot 5$ \\
\hline HOMA-IR & $3 \cdot 1$ & $5 \cdot 5$ & $0.25^{\star}$ & $<0.001$ & 339 & \\
\hline Fasting C-peptide (nmol/l) & 0.9 & 0.6 & $0 \cdot 17^{\star}$ & 0.002 & 336 & $0.13-0.73$ \\
\hline Alanine aminotransferase $(\mathrm{U} / \mathrm{l})$ & $27 \cdot 2$ & $38 \cdot 3$ & -0.95 & 0.076 & 348 & $10-34$ \\
\hline Aspartate aminotransferase (U/I) & $26 \cdot 8$ & $26 \cdot 5$ & $-0 \cdot 12^{*}$ & 0.023 & 346 & $10-44$ \\
\hline
\end{tabular}

HOMA-IR, homeostasis model assessment of insulin resistance.

${ }^{*} P<0.05$.

†See Fisher ${ }^{(13)}$

$\ddagger$ See Kliegman et al. ${ }^{(9)}$. 
Table 2. Associations of serum leptin levels $(\mathrm{ng} / \mathrm{ml})$ (Mean values and standard deviations)

\begin{tabular}{|c|c|c|c|}
\hline & \multicolumn{2}{|c|}{ Leptin } & \multirow[b]{2}{*}{$P \dagger$} \\
\hline & Mean & SD & \\
\hline Sex $^{*}$ & & & 0.003 \\
\hline Girls & $48 \cdot 0$ & $27 \cdot 1$ & \\
\hline Boys & $34 \cdot 4$ & $22 \cdot 4$ & \\
\hline Tanner stage* & & & 0.035 \\
\hline I-II & $37 \cdot 0$ & $22 \cdot 3$ & \\
\hline III-V & $45 \cdot 2$ & $29 \cdot 6$ & \\
\hline Acanthosis nigricans & & & 0.79 \\
\hline Present & $40 \cdot 1$ & $26 \cdot 4$ & \\
\hline Absent & $42 \cdot 4$ & $25 \cdot 9$ & \\
\hline Systolic blood pressure ${ }^{*}$ & & & 0.009 \\
\hline Normal & $41 \cdot 3$ & $23 \cdot 1$ & \\
\hline High & $44 \cdot 0$ & $27 \cdot 4$ & \\
\hline Diastolic blood pressure & & & $0 \cdot 11$ \\
\hline Normal & $42 \cdot 0$ & $23 \cdot 9$ & \\
\hline High & $43 \cdot 3$ & $29 \cdot 4$ & \\
\hline Steatosis in abdominal ultrasound & & & 0.55 \\
\hline Present & 43.5 & 21.9 & \\
\hline Absent & $41 \cdot 2$ & 21.9 & \\
\hline Non-alcoholic fatty liver disease & & & 0.74 \\
\hline Present & $40 \cdot 9$ & $24 \cdot 0$ & \\
\hline Absent & 41.9 & 24.8 & \\
\hline Total cholesterol & & & 0.35 \\
\hline Normal & 41.7 & $25 \cdot 7$ & \\
\hline High & 38.2 & $24 \cdot 3$ & \\
\hline HDL & & & 0.64 \\
\hline Normal & $41 \cdot 2$ & $26 \cdot 0$ & \\
\hline Low & $39 \cdot 2$ & $22 \cdot 3$ & \\
\hline LDL & & & 0.06 \\
\hline Normal & 46.9 & $26 \cdot 6$ & \\
\hline High & 36.5 & $20 \cdot 9$ & \\
\hline TAG & & & 0.62 \\
\hline Normal & 41.7 & $26 \cdot 7$ & \\
\hline High & $40 \cdot 0$ & $23 \cdot 2$ & \\
\hline
\end{tabular}

${ }^{*} P<0.05$.

†By $t$ test.

$z$-score $(r 0 \cdot 145 ; P=0 \cdot 046)$, C-peptide $(r 0.309 ; P<0 \cdot 001)$, insulin $(r 0.335 ; P<0.001)$ and HOMA-IR $(r 0.248 ; P=0 \cdot 001)$.

In the multivariate analysis, with leptin as the dependent variable and the variables with significant associations as independent variables, being female $(P=0 \cdot 012)$ and greater BMI $(P=0.006)$ were determinant factors (Table 3$)$. The associations between leptin and sex and between leptin and BMI $z$-score are shown in Figs. 1 and 2.

Table 3. Linear regression analysis with serum leptin as the dependent variable

\begin{tabular}{lcc}
\hline & Standardised $\beta$ coefficients & $P$ \\
\hline Sex & 0.186 & $0.012^{*}$ \\
BMI z-score & 0.205 & $0.006^{*}$ \\
Tanner stage & 0.106 & 0.197 \\
Systolic blood pressure (mmHg) & 0.074 & 0.327 \\
Fasting insulin (pmol/l) & 0.403 & 0.296 \\
HOMA-IR & -0.147 & 0.711 \\
Fasting C-peptide (nmol/l) & -0.038 & 0.626 \\
Aspartate aminotransferase (U/l) & -0.109 & 0.123 \\
\hline
\end{tabular}

HOMA-IR, homeostasis model assessment of insulin resistance.

${ }^{*} P<0.05$.

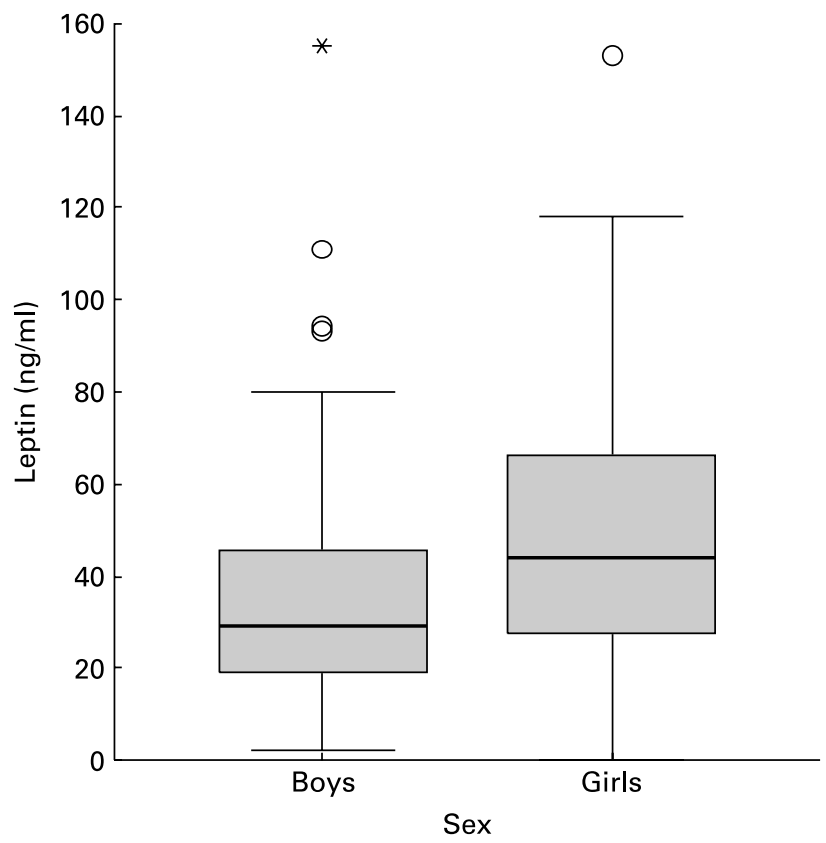

Fig. 1. Relationship between serum leptin concentration $(\mathrm{ng} / \mathrm{ml})$ and sex. The central line is the mean; the box represents the lower and upper quartiles; the whisker shows the maximum and minimum values; $O$, outliers; * outlier excluded from analysis. The mean leptin concentration for girls was $48.0 \mathrm{ng} / \mathrm{ml}$; for boys it was boys $34.4 \mathrm{ng} / \mathrm{ml}$ ( $P=0.003$; $t$ test).

After 6 months of follow-up ( $n$ 286), with dietary and exercise recommendations and without any pharmacological treatment, the mean z-score BMI was 1.58 (SD 1.08); in girls it was 1.57 (SD 1.11) and in boys it was 1.59 (SD 1.05). Both in girls and in boys it was significantly lower than that at the first visit $(P<0.001$ and $P=0 \cdot 017$ respectively) but the difference had no correlation with serum leptin levels.

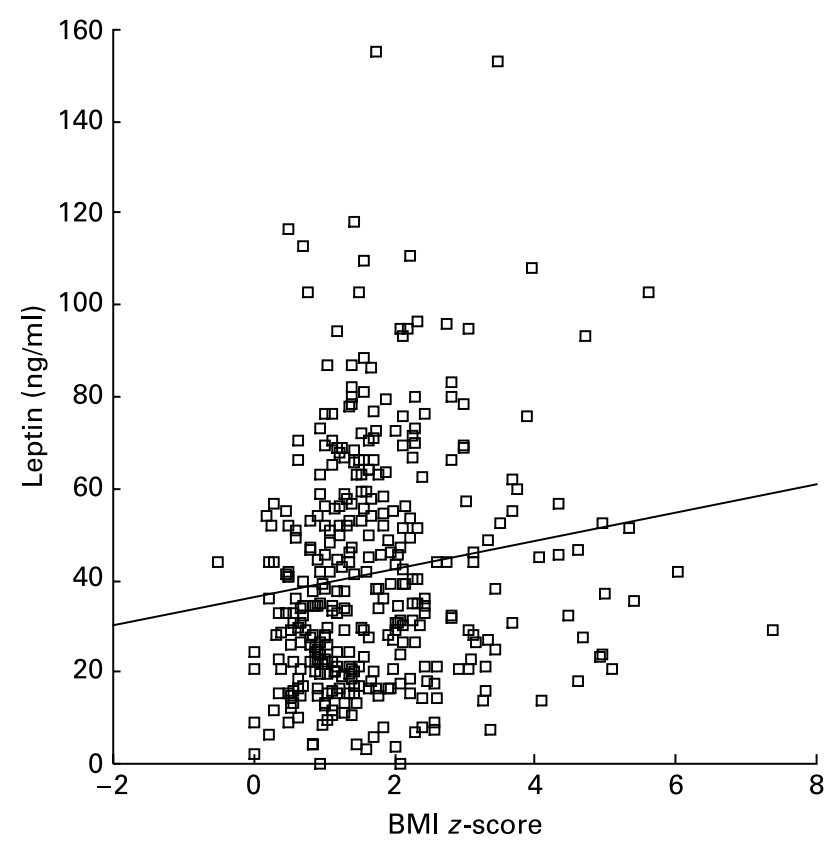

Fig. 2. Relationship between serum leptin concentration ( $\mathrm{ng} / \mathrm{ml})$ and $\mathrm{BMI}$ $z$-score ( $r 0.136 ; P=0.010$; Pearson's test). 


\section{Discussion}

Our work shows several significant associations of clinical and biochemical parameters with serum leptin, but in a multivariate analysis only being female and increased BMI remain significant. As serum leptin correlates only with clinical variables, it was excluded in the obesity protocol of the Gastroenterology and Nutrition Unit of our Hospital after this result.

We exhibit evidence that girls have higher leptin levels than boys, as previously reported in obese $\mathrm{e}^{(6,14)}$ and non-obese $\mathrm{f}^{(15)}$ children and adolescents. This difference increases through puberty as leptin increases from Tanner stage $\mathrm{I}$ to $\mathrm{V}$ in $\operatorname{girls}^{(16)}$; this might be explained at least in part by the higher testosterone levels in males which have a negative effect on leptin concentrations ${ }^{(14,17)}$. Our data also reveal significantly higher leptin in Tanner stages III-V when compared with Tanner stages I-II.

The present study confirms previous findings of a positive correlation between serum leptin levels and $\mathrm{BMI}^{(5,6,14,16-18)}$ even after adjustment for age. Although it seems contradictory, because high leptin concentrations should inhibit additional increases in fat mass, this might be indicative of leptin resistance ${ }^{(7)}$.

If we compare males and females separately, BMI $z$-score no longer has significant association with leptin in boys but it can be due to the association of a weaker relationship in boys ( $r$ 0.142) compared with girls $(r$ 0.145) and a smaller number of patients (166 compared with 190 girls). After adjustment, BMI $z$-score remains with a positive correlation with leptin levels.

We observed a positive association between serum leptin concentrations and waist circumference as previously described ${ }^{(5,6)}$ but it disappeared after adjustment for age.

The relationship between leptin levels and high systolic blood pressure as described in boys in a former study ${ }^{(5)}$ was no longer present after adjustment.

In contrast to a significant relationship between leptin and insulin resistance independently of body fatness described ${ }^{(5)}$, we observed a significant association between leptin and fasting insulin and insulin resistance, but it also disappeared after multivariate analysis, as these parameters were associated with higher BMI.

It was important to perform multivariate analysis to exclude relationships between variables other than leptin, as verified with fasting insulin, insulin resistance, high systolic blood pressure and greater BMI.

We found no association between leptin and lipid profile as previous reported ${ }^{(6)}$; nevertheless, there are data describing a significant correlation with $\mathrm{TAG}^{(5)}$.

Although we did not find any relationship between BMI variation at 6 months and leptin, there are small investigations that found a negative correlation between leptin and weight gain ${ }^{(19)}$ and some other studies found higher leptin levels to predict weight gain over time ${ }^{(7,20,21)}$, which could be explained by the relationship between higher initial BMI and less adherence to diet and exercise and consequently weight gain, but there is one large study ( $n$ 263) in which this relationship was independent of initial $\mathrm{BMI}^{(19)}$.

In conclusion, we confirmed that girls have higher leptin levels than boys independently of the degree of obesity and that fasting serum leptin has a positive correlation with BMI independently of sex. Although leptin levels should not be regarded a less valuable parameter because of the associations found with anthropometrics or sex as it implicates endocrine changes, we do not consider that serum leptin levels should be included in the investigation protocol of our obese patients. In this large paediatric cohort other associations with leptin described in the literature can be discharged.

\section{Acknowledgements}

There are not any conflicts of interests in the present study. H. A. is the specialist that follows the patients included in the study and is the head of the Gastroenterology, Hepatology and Nutrition Unit. H. A. designed the study, performed the statistical analysis and wrote and reviewed the manuscript. C. S. reviewed the statistical analysis. S. C. entered some of the patients into the database and measured the leptin levels, performed the statistical analysis and wrote the manuscript.

\section{References}

1. Ogden CL, Carroll MD, Curtin LR, McDowell MA, Tabak CJ \& Flegal KM (2006) Prevalence of overweight and obesity in the United States, 1999-2004. JAMA 295, 1549-1555.

2. Padez C, Fernandes T, Mourão I, Moreira P \& Rosado V (2004) Prevalence of overweight and obesity in 7-9 year-old Portuguese children: trends in body mass index from 1970-2002. Am J Hum Biol 16, 670-678.

3. Baptista C (2002) Leptina (Leptin). Acta Pediatr Port 15, $281-285$

4. Moran O \& Phillip M (2003) Leptin: obesity, diabetes and other peripheral effects - a review. Pediatr Diabetes 4, 101-109.

5. Steinberger J, Steffen L, Jacobs DR Jr, Moran A, Hong CP \& Sinaiko AR (2003) Relation of leptin to insulin resistance syndrome in children. Obes Res 11, 1124-1130.

6. Pilcová R, Sulcová J, Hill M, Bláha P \& Lisá L (2003) Leptin levels in obese children: effects of gender, weight reduction and androgens. Physiol Res 52, 53-60.

7. Johnson MS, Huang TT, Figueroa-Colon R, Dwyer JH \& Goran MI (2001) Influence of leptin on changes in body fat during growth in African American and white children. Obes Res 9, 593-598.

8. Ramesh S \& Sanyal AJ (2005) Evaluation and management of non-alcoholic steatohepatitis. J Hepatol 42, Suppl. 1, S2-S12.

9. Kliegman RM, Behrman RE, Jenson HB \& Stanton BF (2007) Nelson Textbook of Pediatrics, 18th ed. Philadelphia, PA: Saunders.

10. Centers of Disease Control (2000) NHANES - United States Growth Charts - Data Files: Clinical Growth Charts. http://www. cdc.gov/nchs/about/major/nhanes/growthcharts/clinical_charts.htm (accessed 29 June 2007).

11. McDowell MA, Fryar CD, Hirsch R \& Ogden CL (2005) Anthropometric reference data for children and adults: U.S. population, 1999-2002. Adv Data 361, 1-5.

12. Schwimmer JB, Deutsch R, Rauch JB, Behling C, Newbury R \& Lavine JE (2003) Obesity, insulin resistence, and other clinicopathological correlates of pediatric nonalcoholic fatty liver disease. J Pediatr 143, 500-505.

13. Fisher DA (2000) Alphabetical test listing (leptin). In The Quest Diagnostics Manual: Pediatric Endocrinology Tests and 
Methods, Specimen Requirements, Test Selection and Interpretation, p. 56 Madison, NJ: Quest Diagnostics.

14. Wabitsch M, Blum WF, Muche R, Braun M, Hube F, Rascher W, Heinze E, Teller W \& Hauner H (1997) Contribution of androgens to the gender difference in leptin production in obese children and adolescents. J Clin Invest 100, 808-813.

15. Garcia-Mayor RV, Andrade MA, Rios M, Lage M, Dieguez C \& Casanueva FF (1997) Serum leptin levels in normal children: relationship to age, gender, body mass index, pituitary-gonadal hormones, and pubertal stage. J Clin Endocrinol Metab 82 2849-2855.

16. Carlsson B, Ankarberg C, Rosberg S, Norjavaara E, AlbertssonWikland K \& Carlsson LM (1997) Serum leptin concentrations in relation to pubertal development. Arch Dis Child 77, 396-400.

17. Blum WF, Englaro P, Hanitsch S, et al. (1997) Plasma leptin levels in healthy children and adolescents: dependence on body mass index, body fat mass, gender, pubertal stage and testosterone. J Clin Endocrinol Metab 82, 2904-2910.
18. Stylianou C, Galli-Tsinopoulou A, Farmakiotis D, Rousso I, Karamouzis M, Koliakos G \& Nousia-Arvanitakis S (2007) Ghrelin and leptin levels in obese adolescents. Relationship with body fat and insulin resistance. Hormones (Athens) $\mathbf{6}$, 295-303.

19. Byrnes SE, Baur LA, Bermingham M, Brock K \& Steinbeck K (1999) Leptin and total cholesterol are predictors of weight gain in pre-pubertal children. Int $J$ Obes Relat Metab Disord 23, $146-150$.

20. Fleisch AF, Agarwal N, Roberts MD, Han JC, Theim KR, Vexler A, Troendle J, Yanovski SZ \& Yanovski JA (2007) Influence of serum leptin on weight and body fat growth in children at high risk for adult obesity. J Clin Endocrinol Metab 92, 948-954.

21. Savoye M, Dziura J, Castle J, DiPietro L, Tamborlane WV \& Caprio S (2002) Importance of plasma leptin in predicting future weight gain in obese children: a two-and-a-half-year longitudinal study. Int J Obes Relat Metab Disord 26, 942-946. 